\title{
СУЩЕСТВУЕТ ЛИ МЕТАБОЛИЧЕСКИ ЗДОРОВОЕ ОЖИРЕНИЕ?
}

\author{
Ганенко Л.А., Зибарев А.Л.
}

ФГБОУ ВО Ростовский государственный медицинский университет Минздрава России, Ростов-на-Дону

АКТУАЛЬНОСТЬ: распространенность ожирения растет во всем мире. Прогнозируется, что к 2030 г. почти 40\% населения мира будет иметь избыточный вес, а каждый пятый будет страдать ожирением. Ожирение является важным фактором риска сердечно-сосудистых заболеваний, сахарного диабета 2 типа. Однако не все пациенты с ожирением имеют неблагоприятный кардиометаболический профиль. В последнее время большое внимание уделяется концепции «метаболически здорового ожирения» (М30). МЗО характеризуется отсутствием метаболических нарушений, таких как дислипидемия, инсулинорезистентность, артериальная гипертония и неблагоприятный воспалительный профиль. В современной литературе появляется все больше фактов, указывающих, что микробиом кишечника и адипомиокиновый профиль являются потенциальными факторами, участвующими в патофизиологии как ожирения, так и связанных с ним нарушений обмена веществ.

ЦЕЛЬ: Выявление особенностей адипомиокинового профиля и его связь с показателями разнообразия микробиома кишечника у пациентов с разными фенотипами ожирения.

МАТЕРИАЛЫ И МЕТОДЫ: Обследовано 265 мужчин и женщин старше 18 лет. Сформированы 2 основные клинические группы: группа 1 - здоровые люди с нормальной массой тела, группа 2 - пациенты с ожирением, далее пациенты 2 группы (ожирение) были разделены на дополнительные 2 подгруппы в зависимости от метаболического профиля: подгруппа 2a - пациенты с М30, подгруппа 26 - пациенты с МН3О. Всем обследуемым рассчитывался индекса массы тела, определялась окружность талии, оценивалось состояние липидного и углеводного обмена, рассчитывался индекс HOMA-IR (Homeostasis Model Assessment of Insulin Resistance), определялся уровень адипокинов и миокинов в сыворотки крови и состав микробиома кишечника, рассчитанывались индексы альфа разнообразия по филотипам бактерий.

РЕЗУЛЬТАТЫ: выявлены статистически значимые различия содержания исследуемых адипокинов и миокинов, а также взаимосвязь адипомиокинового профиля с показателями разнообразия микробиома кишечника у пациентов с разными фенотипами ожирения.

Выводы: полученные результаты указывают на изменения профилей адипомиокинов и индексов разнообразия микробиома кишечника у пациентов с разными фенотипами ожирения. 